\title{
Pengaruh Bauran Pemasaran Dan Kualitas Layanan Terhadap Keputusan Pembelian Di Calais Artisan Bubble Tea \&Coffee Manokwari
}

\author{
Tifanny Lamria Sihole ${ }^{1}$, Selmi Dedi² ${ }^{2}$ Louis S Bopeng ${ }^{3}$ \\ ${ }^{1}$ Alumni Jurusan Manajemen, Universitas Papua \\ ${ }^{2,3}$ Dosen Jurusan Manajemen, Universitas Papua
}

Received: Juli 2020; Accepted: Agustus 2020; Published: September 2020

\begin{abstract}
Abstrak
Tujuan penelitian ini adalah untuk mengidentifikasi pengaruh antara variabel bauran pemasaran (X1), kualitas layanan (X2) terhadap keputusan pembelian (Y) di Calais Artisan Bubble Tea \& Coffee Manokwari. Metode penelitian yang digunakan adalah metode purposive sampling, banyaknya sampel yang diteliti adalah 100 responden yang merupakan konsumen di Calais Artisan Bubble Tea \& Coffee Manokwari. Teknik penentuan sampel yang digunakan dalam penelitian ini adalah dengan rumus Malholtra. Berdasarkan hasil penelitian diperoleh kesimpulan bahwa persamaan regresi linear berganda untuk pengaruh bauran pemasaran dan kualitas layanan terhadap keputusan pembelian adalah $\mathrm{Y}=1,794+0,125 \mathrm{X} 1+0,429 \mathrm{X} 2$. Bauran pemasaran berpengaruh terhadap keputusan pem belian berdasarkan thitung $(4,908)>$ ttabel $(1,988)$. Sedangkan secara simultan bauran pemas aran dan kualitas layanan berpengaruh signifikan terhadap keputusan pem belian karena nilai fhitung $(98,154)>$ ftabel $(3,09)$ dan koefisien determinasi (R Square) adalah 0,669.
\end{abstract}

Kata kunci: bauran pemasaran, kualitas layanan, keputusan pembelian

\begin{abstract}
Purpose of this research is toidentify the influence between the variable for Marketing Mix (XI), and Service Quality (X2) affect in Purchase (Y) in Calais Artisan Bubble Tea \& Coffee Manokwari. The accuration method whice use are purposive sampling method. The number of samples studied were 100 respondents who are consumers of Calais Artisan Bubble Tea \& Coffee Manokwari. Based on the results of the study concluded that the multiple linear regresions equation for the effect of marketing mix and service quality on purchasing decisions $Y=1,794+0,125 X 1+0,429 X 2$. Marketing mix in fluence the purchasing decisions based on thitung $(4,908)>$ ttabel $(1,988)$. While simultaneously marketing mix and service quality significantly influence the purchasing decisions because the value of fhitung $(98,154)>f t a b e l(3,09)$ and determinant coefficient $(R$ Square) is 0,669.
\end{abstract}

Keywords: marketing mix, service quality, purchasing decisions process

How to Cite: Sihole., L., T., Dedi., S., Bopeng., S., L., (2020). Pengaruh Bauran Pemasaran Dan Kualitas Layanan Terhadap Keputusan Pembelian Di Calais Artisan Bubble Tea \&Coffee Manokwari. JFRES: Journal of Fiscal and Regional Economy Studies, 3 (2), 11 - 17.

\footnotetext{
Corresponding author :

E-mail: louis.bopeng@gmail.com
} 


\section{PENDAHULUAN}

Meningkatnya pertumbuhan ekonomi dan kebutuhan konsumen yang berdaya beli kuat membuat pola belanja di Indonesia saat ini berubah dan berkembang sebagai cerminan gaya hidup yang lebih modern dan lebih berorientasi pada rekreasi yang mementingkan aspek kesenangan, kenikmatan dan hiburan saat berbelanja (Parwanto, 2006).

Perindustrian di Indonesia merupakan salah satu komponen perekonomian yang berkembang pesat dalam peningkatan kondisi perekonomian nasional. Salah satu industri yang sedang berkembang di Indonesia saat ini adalah industri food and beverages. Peluang bisnis minuman masih sangat segar untuk dilakoni mengingat iklim cuaca di Indonesia yang cenderung tropis atau hangat. Produk-produk minuman yang menyegarkan tentu amat cocok dikonsumsi oleh masyarakat tanah air, terlebih bagi mereka yang menyukai berkumpul bersama keluarga atau bersama rekan.

Terdapat bermacam-macam bisnis minuman salah satunya adalah bisnis cafe dan bisnis coffee shop. Bisnis minuman yang masih digandrungi oleh masyarakat yaitu Calais Artisan Bubble Tea dan Coffee. Produk minuman Calais Artisan Bubble Tea dan Coffee selalu berkembang dalam menciptakan konsep baru untuk produk Bubble Tea dan Coffee di masyarakat perkotaan yang serba cepat.

Selain bauran pemasaran (marketing mix), kemampuan perusahaan dalam memberikan pelayanan terhadap konsumen dapat menjadi pusat keuntungan perusahaan. Pelayanan adalah setiap kegiatan atau manfaat yang ditawarkan suatu pihak pada pihak lain yang tidak berwujud dan tidak mengakibatkan kepemilikan apapun. Produksi layanan bisa berhubungan dengan produksi fisik maupun tidak (Bilson Simamora, 2001). Berdasarkan masalah tersebut, maka peneliti ingin melakukan penelitian dengan judul "Pengaruh Bauran Pemasaran dan Kualitas Layanan Terhadap Keputusan Pembelian di Calais Artisan Bubble Tea dan Coffee Manokwari”.

\section{Rumusan Masalah}

Berdasarkan latar belakang yang telah dikemukakan diatas, maka dapat dirumuskan permasalahan-permasalahan sebagai berikut :
1. Apakah bauran pemasaran berpengaruh terhadap keputusan pembelian?

2. Apakah kualitas layanan berpengaruh terhadap keputusan pembelian?

3. Apakah bauran pemasaran dan kualitas layanan berpengaruh secara simultan terhadap keputusan pembelian?

\section{METODE PENELITIAN}

\section{Jenis Penelitian}

Jenis penelitian yang digunakan dalam penelitian ini adalah penelitian kuantitatif. Penelitian kuantitatif menurut tingkat eksplanasinya yaitu penelitian asosiatif. Menurut Sugiyono (2014), penelitian asosiatif merupakan penelitian yang bertujuan untuk mengetahui pengaruh ataupun hubungan antara dua variabel atau lebih.

\section{Tempat dan Waktu Penelitian}

Penelitian ini dilakukan pada Calais Artisan Bubble Tea dan Coffee yang berlokasi di Jl. Jendral Sudirman, Kelurahan Padarni, Distrik Manokwari Barat, KabupatenManokwari, Provinsi Papua Barat. Penelitian ini dilakukan selama satu bulan terhitung dari tanggal $22 \mathrm{Mei}-$ 23 Juni 2018.

\section{Populasi dan Sampel Penelitian}

Populasi yang peneliti ambil yaitu konsumen yang telah melakukan pembelian di Calais Artisan Bubble Tea dan Coffee Manokwari. Sedangkan sampel dalam penelitian ini adalah masyarakat Manokwari yang sudah pernah berkunjung ke Calais Artisan Bubble Tea dan Coffee.

Dalam hal ini penulis mengambil pertimbangan bahwa sampel adalah responden yang berkunjung 2 sampai 5 kali bahkan bisa lebih dari itu. Tidak diketahui jumlah populasi, oleh sebab itu penulis menggunakan rumus Maholtra dalam penentuan sampel dalam penentuan sampel, rumus Maholtra (2005) adalah:

$$
\mathrm{n}=5 \mathrm{x} \text { jumlah item pertanyaan }
$$

$\mathrm{n}=5 \times 20$

$\mathrm{n}=100$

Berdasarkan hasil perhitungan yang menggunakan rumus Maholtra maka jumlah sampel yang akan diteliti adalah 100 responden. 


\section{Jenis dan Sumber Data}

Jenis dan sumber data yang dipakai dalam penelitian ini adalah :

\section{Data Primer}

Adalah data yang diperoleh dari sumber informasi yang mana peneliti sendiri yang menetukan siapa sumber informasinya.

\section{Data Sekunder}

Adalah data yang diperoleh dari data yang sudah ada yaitu melalui catatan atau dokumentasi perusahaan, internet, situs WEB serta informasi pemerintah yang dipublikasikan.

\section{Metode Pengumpulan Data}

Metode pengumpulan data yang digunakan dalam penelitian ini adalah :

\section{Kuesioner}

Suatu teknik pengumpulan data yang dilakukan dengan cara memberikan seperangkat pernyataan tertulis kepada responden untuk dijawab.

\section{Observasi}

Mendatangi langsung lokasi penelitian sebelum penelitian dilakukan maupun saat penelitian berlangsung.

\section{Studi Pustaka}

Teknik pengumpulan data dan informasi dengan melakukan kegiatan kepustakaan melalui bukubuku, jurnal dan sebagainya yang berkaitan dengan tujuan penelitian.

\section{Definisi Operasional dan Pengukurannya}

Variabel yang digunakan dalam penelitian ini adalah :

1. Variabel Bebas (independent variabel) X1, Bauran Pemasaran

Kotler (2008), bahwa bauran pemasaran (marketing mix) adalah seperangkat alat pemasaran yang digunakan perusahaan untuk terus menerus mencapai tujuan pemasarannya di pasar sasarannya. Bauran pemasaran harus bersifat dinamis dan dapat menyesuaikan diri dengan lingkungan eksternal maupun internal. Faktor eksternal yaitu faktor diluar jangkauan perusahaan. Contohnya pesaing, teknologi, peraturan pemerintah, keadaan perekonomian, dan lingkungan sosial budaya. Faktor internal yaitu faktor didalam perusahaan. Contohnya produk, harga, promosi dan tempat atau saluran distribusi. Sehingga dalam penelitian ini peneliti mengambil faktor internal sebagai dimensi pada bauran pemasaran, peneliti beraggapan bahwa faktor internal merupakan faktor dasar seseorang jika mau melakukan suatu usaha bisnis.

X1.1.Produk yaitu: barang dan jasa yang digunakan untuk memenuhi kebutuhan.

$\mathrm{X} 1.2$.Harga yaitu: aspek yang tampak jelas bagi para pembeli

X1.3.Promosi yaitu: penawaran produk untuk menarik calon konsumen

X1.4.Tempat yaitu: lokasi yang dipilih perusahaan untuk mendirikan usaha.

2. Variabel Bebas (independent variabel) X2,

Kualitas Layanan

Kualitas layanan dapat didefinisikan sebagai seberapa jauh perbedaan antara kenyataan dan harapan pelanggan atas layanan yang diterima pelanggan. Parasuraman (1998).

X2.1.Keberwujudan yaitu: kemampuan perusahaan untuk menampilkan yang terbaik bagi pelanggan

X2.2.Keandalan yaitu: kemampuan perusahaan untuk memberikan pelayanan yang sesuai harapan konsumen.

X2.3.Ketanggapan yaitu: tanggap memberikan pelayanan yang cepat

X2.4.Jaminan yaitu: kepastian yang diperoleh dari sikap sopan santun karyawan.

X2.5.Empati yaitu: memberikan perhatian yang tulus dan bersifat pribadi kepada pelanggan.

3. Variabel Terikat (dependent variabel) Y, keputusan pembelian

Variabel dependen adalah variabel yang mempengaruhi atau menjadi akibat dikarenakan adanya variabel independen (Sugiyono, 2014). Variabel dependen dalam penelitian ini yaitu keputusan pembelian. Kotler (1996), keputusan pembelian adalah tindakan dari konsumen untuk mau membeli atau tidak terhadap produk. Indikator yang akan digunakan dalam item pertanyaan keputusan pembelian yaitu :

Y1.1.Kemantapan pada sebuah produk yaitu: Konsumen dalam pengambilan

keputusan pembelian harus dapat menentukan pilihannya terhadap produk yang diinginkan.

Y1.2.Kebiasaan dalam membeli produk yaitu: Kebiasaan konsumen biasanya didasari dengan penggunaan dari produk tersebut sebelumnya. 
Y1.3.Memberikan rekomendasi pada orang lain yaitu: pelanggan secara tidak langsung merasakan kepuasan dari produk dan akan mampu merekomendasikan produk tersebut pada orang disekitarnya.

Y1.4.Melakukan pembelian ulang yaitu: Konsumen yang merasa puas akan suatu produk tertentu pastinya akan melakukan pembelian ulang terhadap produk tersebut.

\section{Regresi Linear Berganda}

Dalam penelitian ini peneliti menggunakan metode analisis regresi linear berganda. Alat analisis bertujuan untuk mengukur kekuatan hubungan antara satu variabel maupun lebih dari satu, baik itu variabel dependen maunpun independen.(Ghozali, 2009).

Persamaan regresi yang digunakan adalah sebagai berikut :

$$
Y=\alpha+\beta_{1} X_{1}+\beta_{2} X_{2}+e
$$

Keterangan :

$\mathrm{Y}=$ keputusan pembelian

$\alpha=$ konstanta

$\mathrm{X} 1=$ Bauran Pemasaran

$\mathrm{X} 2$ = Kualitas Layanan

$\beta 1, \beta 2=$ koefisien regresi variabel

$\mathrm{e}=$ Standar Error

\section{HASIL PENELITIAN}

\section{Uji Validitas}

Berdasarkan Tabel 1 uji validitas menunjukkan hasil dari variable bauran pemasaran, variabel kualitas pelayanan terhadap keputusan pembelian dinyatakan valid karena Pearson Correlation > 0,5 .

Tabel 1. Hasil Uji Validitas Kuesioner

\begin{tabular}{llccc}
\hline Variabel & \multicolumn{1}{c}{ Pernyataan } & $\begin{array}{c}\text { Pearson } \\
\text { Correlation }\end{array}$ & $\begin{array}{c}\text { Cut Of } \\
\text { Point }\end{array}$ & Keterangan \\
\hline Bauran Pemasaran (X1) & Produk1 & 0,844 & 0,5 & Valid \\
& Produk 2 & 0,831 & 0,5 & Valid \\
& Produk 3 & 0,812 & 0,5 & Valid \\
& Harga 1 & 0,833 & 0,5 & Valid \\
& Harga 2 & 0,831 & 0,5 & Valid \\
& Promosi 1 & 0,796 & 0,5 & Valid \\
& Promosi 2 & 0,822 & 0,5 & Valid \\
& Promosi 3 & 0,779 & 0,5 & Valid \\
& Lokasi 1 & 0,829 & 0,5 & Valid \\
& Lokasi 2 & 0,773 & 0,5 & Valid \\
Kualitas Layanan (X2) & Lokasi 3 & 0,748 & 0,5 & Valid \\
& Keberwujudan & 0,818 & 0,5 & Valid \\
& Keandalan & 0,760 & 0,5 & Valid \\
& Ketanggapan & 0,654 & 0,5 & Valid \\
& Jaminan & 0,652 & 0,5 & Valid \\
Keputusan & Empati & 0,776 & 0,5 & Valid \\
(Y) & Kemantapan Produk & 0,738 & 0,5 & Valid \\
& Kebiasaan & 0,787 & 0,5 & Valid \\
& Rekomendasi & 0,667 & 0,5 & Valid \\
& Pembelian Ulang & 0,735 & 0,5 & Valid \\
\hline
\end{tabular}

Sumber: Data Primer yang Diolah, 2019

\section{Uji Reliabilitas}

Berdasarkan tabel 2 hasil uji reabilitas dari variabel bauran pemasaran, kulalitas pelayanan, terhadap keputusan pembelian yaitu reliabel karena Cronbach Alpha $\geq 0,60$.
Tabel 2. Hasil Uji Reliabilitas

\begin{tabular}{lccc}
\hline \multicolumn{1}{c}{ Varaibel } & $\begin{array}{c}\text { Cronbach } \\
\text { Alpha }\end{array}$ & $\begin{array}{c}\text { Cut } \\
\text { Of } \\
\text { Point }\end{array}$ & Ket. \\
\hline Bauran Pemasaran (X1) & 0,882 & 0,60 & Reliabel \\
Kualitas Layanan (X2) & 0,786 & 0,60 & Reliabel \\
Keputusan Pembeli (Y) & 0,731 & 0,60 & Reliabel \\
\hline
\end{tabular}

Sumber: Data Primer yang diolah, 2019

\section{Regresi Linear Berganda}


Tabel 3. Hasil Analisis Regresi Linear Berganda

\begin{tabular}{|c|c|c|c|c|c|}
\hline \multirow{3}{*}{ Model } & \multicolumn{3}{|c|}{ Coefficients $^{\mathrm{a}}$} & \multirow{3}{*}{$\mathrm{T}$} & \multirow{3}{*}{ Sig. } \\
\hline & \multicolumn{2}{|c|}{$\begin{array}{l}\text { Unstandardized } \\
\text { Coefficients }\end{array}$} & $\begin{array}{c}\text { Standardized } \\
\text { Coefficients }\end{array}$ & & \\
\hline & $\mathrm{B}$ & Std. Error & Beta & & \\
\hline (Constant) & 1,794 & 0,754 & & 2,379 & 0,019 \\
\hline Bauran Pemasaran X1 & 0,125 & 0,042 & 0,320 & 2,964 & 0,004 \\
\hline Kualitas Layanan X2 & 0,429 & 0,087 & 0,530 & 4,908 & 0,000 \\
\hline
\end{tabular}

a. Dependent Variable: Keputusan Pembelian

Sumber: Data Primer yang diolah, 2019

\section{Koefisien Determinasi (R2)}

Tabel 4. Hasil Uji Koefisien Determinasi (R2)

Model Summary ${ }^{\mathrm{b}}$

\begin{tabular}{ccccc}
\hline Model & $\mathrm{R}$ & R Square & Adjusted R Square & Std. Error of the Estimate \\
\hline 1 & $0,818^{\mathrm{a}}$ & 0,669 & 0,662 & 1,810 \\
\hline
\end{tabular}

a. Predictors: (Constant), Kualitas Layanan, Bauran Pemasaran

b. Dependent Variable: Keputusan Pembelian

Sumber: Data Primer yang diolah, 2019

\section{Hasil Uji Secara Parsial (Uji T)}

Tabel 5. Hasil Pengujian Secara Parsial (Uji T)

\begin{tabular}{lccccc}
\hline \multirow{2}{*}{ Model } & \multicolumn{5}{c}{ Coefficients $^{\mathrm{a}}$} \\
& Unstandardized Coefficients & $\begin{array}{c}\text { Standardized } \\
\text { Coefficients }\end{array}$ & T & Sig. \\
\cline { 2 - 6 } & $\mathrm{B}$ & Std. Error & Beta & & \\
\hline (Constant) & 1,794 & 0,754 & & 2,379 & 0,019 \\
\hline Bauran Pemasaran & 0,125 & 0,042 & 0,320 & 2,964 & 0,004 \\
\hline Kualitas Layanan & 0,429 & 0,087 & 0,530 & 4,908 & 0,000 \\
\hline
\end{tabular}

a. Dependent Variable: Keputusan Pembelian

Sumber: Data Primer yang diolah, 2019

\section{Hasil Uji Secara Simultan (Uji F)}

Tabel 6. Hasil Pengujian Secara Simultan (Uji F) ANOVA $^{\mathrm{a}}$

\begin{tabular}{lcrrrl}
\hline Model & Sum of Squares & Df & Mean Square & F & Sig. \\
\hline Regression & 643,020 & 2 & 321,510 & 98,154 & $0,000^{\mathrm{b}}$ \\
\hline Residual & 317,730 & 97 & 3,276 & & \\
\hline Total & 960,750 & 99 & & & \\
\hline
\end{tabular}

a. Dependent Variable: Keputusan Pembelian

b. Predictors: (Constant), Kualitas Layanan, Bauran Pemasaran

Sumber: Data Primer yang diolah, 2019

\section{PEMBAHASAN}

Berdasarakan Tabel 3 rumus analisis regresi linear berganda yang diperoleh adalah sebagai berikut:

$\mathrm{Y}=1,794+0,125 \mathrm{X} 1+0,429 \mathrm{X} 2$

Pengaruh Bauran Pemasaran dan Kualitas Layanan Secara Parsial Terhadap Keputusan Pembelian
1. Pengaruh Bauran Pemasaran terhadap Keputusan Pembelian

Berdasarkan hasil pengujian secara parsial yaitu bahwa Variabel bauran pemasaran yaitu nilai $\mathrm{t}$ hitung sebesar 2,964 sedangkan dengan nilai $\mathrm{t}$ tabel sebesar 1,984 dan nilai signifikansi sebesar 0,004 lebih kecil dari nilai $\alpha$ (alpha) yaitu sebesar 0,05. Dari hasil tersebut bahwa dapat disimpulkan bahwa $\mathrm{H} 0$ ditolak dan $\mathrm{H} 1$ diterima yang berarti bahwa bauran pemasaran berpengaruh signifikan terhadap keputusan pembelian di Calais Artisan 
Bubble Tea dan Coffee Manokwari. Selanjutnya dapat disimpulkan bahwa ada 4 (empat) indikator dalam bauran pemasaran yaitu produk,harga,promosi, dan tempat. Dari empat indikator tersebut yang membuat pemebeli senang berkujnjung Calais Artisan Bubble Tea dan Coffee Manokwari karena produknya yang menarik, harga yang terjangkau, promosinya sangat bagus serta tempatnya juga nyaman, sehingga dapat menarik perhatian pembeli terhadap Calais Artisan Bubble Tea dan Coffee Manokwari. Hasil penelitian ini juga sejalan dengan penelitian yang dilakukan oleh Sandy (2015) yang menyatakan bahwa bauran pemasaran (harga, lokasi, produk, promosi, dan kualitas layanan) berpengaruh terhadap keputusan pembelian.

2. Pengaruh Kualitas Layanan Terhadap Keputusan Pembelian

Berdasarkan hasil pengujian secara parsial yaitu bahwa Variabel kualitas Pelayanan yaitu mempunyai nilai t hitung sebesar 4,908 dan nilai $\mathrm{t}$ tabel yaitu sebesar $1,984(4,908>1,984)$ dan nilai signifikansi sebesar 0,000 lebih kecil dari nilai $\alpha$ (alpha) yaitu $0,05(0,000<0,05)$. Dari hasil tersebut dapat disimpulkan bahwa $\mathrm{H}_{0}$ ditolak dan $\mathrm{H}_{2}$ diterima, yang artinya bahwa variabel kualitas layanan (X2) secara parsial berpengaruh terhadap keputusan pembelian $(\mathrm{Y})$ di Calais Artisan Bubble Tea dan Coffee Manokwari. Hasil tersebut dapat disimpulkan bahwa ada 5 (lima) indikator untuk mengukur kualitas pelayanan yang baik bagi perusahaan serta dapat menarik pembeli untuk berkunjung di Calais Artisan Bubble Tea dan Coffee Manokwari, indikator tersebut yaitu (keberwujudan, keandalan, ketanggapan, jaminan dan empati). Hasil pengujian variabel kualitas pelayanan terhadap keputusan pembelian secara parsial adalah kualitas pelayanan mempunyai pengaruh terhadap keputusan pembelian. Hasil penelitian ini sejalan dengan penelitian yang dilakukan oleh ;Aprillia (2015)yang menyatakan bahwa kualitas layanan berpengaruh terhadap keputusan pembelian.

\section{Pengaruh Bauran Pemasaran dan Kualitas Layanan secara Simultan terhadap Keputusan Pembelian}

Berdasarkan hasil pengujian secara parsial dapat di peroleh informasi bahwa variabel bauran pemasaran dan variabel kualitas pelayanan memiliki nilai $\mathrm{F}$ hitung yaitu sebesar 98,154 dan $\mathrm{F}$ tabel sebesar 3,09 yang bererati bahwa nilai $\mathrm{F}$ hitung lebih besar dari nilai $\mathrm{F}$ tabel dan nilai signifikan $0,000<0,05$. Jadi dari hasil tersebut dapat disimpulkan bahwa Ha diterima dan $\mathrm{H} 0$ ditolak, yang merupakan bahwa variabel bauran pemasaran (X1) dan kualitas layanan (X2) secara simultan berpengaruh signifikan terhadap keputusan pembelian (Y).Hasil penelitian ini sejalan dengan penelitian yang dilakukan oleh Masrita (2013) yang menyatakan bahwa yaitu Bauran Pemasaran (produk, harga, promosi) dan Kaulitas Layanan secara bersama-sama terhadap keputusan pembelian di batik Jambi (suatu studi di show room dekranasda Provinsi Jambi).

\section{KESIMPULAN}

Berdasarkan hasil yang diteliti dan pembahasan dapat disimpulkan sebagai berikut:

1. Variabel bauran pemasaran dan kualitas layanan berpengaruh signifikan secara parsial terhadap keputusan pembelian. Berikut penjelasannya:

\section{a. Bauran Pemasaran}

Berdasarkan hasil pengujian secara parsial yaitu bahwa Variabel bauran pemasaran yaitu nilai thitung sebesar 2,964 sedangkan dengan nilai t tabel sebesar 1,984 dan nilai signifikansi sebesar 0,004 lebih kecil dari nilai $\alpha$ (alpha) yaitu sebesar 0,05. Dari hasil tersebut bahwa dapat disimpulkan bahwa $\mathrm{H} 0$ ditolak dan $\mathrm{H} 1$ diterima yang berarti bahwa bauran pemasaran berpengaruh signifikan terhadap keputusan pembelian di Calais Artisan Bubble Tea dan Coffee Manokwari.

b. Kualitas Pelayanan

Berdasarkan hasil pengujian secara parsial yaitu bahwa Variabel kualitas Pelayanan yaitu mempunyai nilai t hitung sebesar 4,908 dan nilai t tabel yaitu sebesar $1,984(4,908>1,984)$ dan nilai signifikansi sebesar 0,000 lebih kecil dari nilai $\alpha$ (alpha) yaitu $0,05(0,000<0,05)$. Dari hasil tersebut dapat disipulkan bahwa HO ditolak dan $\mathrm{H} 2$ diterima, yang artinya bahwa variabel kualitas layanan (X2) secara parsial berpengaruh terhadap keputusan pembelian (Y) di Calais Artisan Bubble Tea dan Coffee Manokwari.

2. Variabel bauran pemasaran dan kualitas layanan berpengaruh signifikan secara simultan terhadap keputusan pembelian. Berikut penjelasannya: 
Hasil pengujian secara parsial dapat di peroleh informasi bahwa variabel bauran pemasaran dan variabel kualitas pelayanan memiliki nilai F hitung yaitu sebesar 98,154 dan F tabel sebesar 3,09 yang bererati bahwa nilai $\mathrm{F}$ hitung lebih besar dari nilai $\mathrm{F}$ tabel dan nilai signifikan $0,000<0,05$. Jadi dari hasil tersebut bisa ditarik kesimpulan jika Ha diterima dan H0 ditolak, yang merupakan bahwa variabel bauran pemasaran (X1) dan kualitas layanan (X2) secara simultan berpengaruh signifikan terhadap keputusan pembelian (Y).

\section{DAFTAR REFERENSI}

Arikunto, Suharsini. 1998, Prosedur Penelitian, Suatu Pendekatan Praktek, Edisi RevisiKelima, Rineke Cipta, Jakarta

Ghozali, Imam. 2009, Aplikasi Analisis Multivariat dengan Program SPSS. Jakarta.PT

Kotler, P., 2008, Manajemen Pemasaran, Edisi 12, 13 Jilid Satu, Dua Alih Bahasa Benyamin Molan, Jakarta

Kotler, Philip. 1996. Manajemen Pemasaran. Jakarta: Erlangga.
Laila, Ida, 2007. Analisis Proses Keputusan Pembelian Dan Evaluasi Tingkat Kepuasan Konsumen Terhadap Pembelian Roti Tawar Merek Le Git di Bogor. Skripsi. Program Ekstensi Manajemen Agribisnis. Institut Pertanian Bogor.

Sitaniapessy, Harry A.P, 2008. Pengaruh Kepuasan Pelanggan Terhadap Niat Pembelian Ulang Di Matahari Departemen Store Ambon, Jurnal volume II, nomor 2, Politeknik Negeri Ambon.

Sugiyono. 2008. Metode Penelitian Bisnis. Bandung: CV Alfabeta.

Sunarto. 2004. Prinsip - Prinsip Pemasaran. Yogyakarta: Amus

Suryana, Endang, 2007. Analisis Tingkat Kepuasan Dan Loyalitas Konsumen Terhadap Produk Minuman Isotonik Merek Pocari Sweat. Skripsi. Program Sarjana Manajemen Agribisnis. Institut Pertanian Bogor.

Wimman Zulfikar, Muhamad. 2011, Analisis Pengaruh Bauran Pemasaran terhadap keputusan Pembelian (Studi Oase Batik Pekalongan. 